\title{
The nature of consciousness and the meaning of life
}

\author{
Michael J Vandeman* \\ The American Biology Teacher, 2600, Camino Ramon \#3s300d, San Ramon, CA, USA
}

\section{Introduction}

"Consciousness is not to be found among physical objects" E. H. Walker, p.147 [1].

"The mind is all the information in the brain. Consciousness is the brain's awareness of some of that information." J. A. Hobson, p.203 [2].

"There is not an iota of evidence that humans have any special role in physical phenomena; there is no credible evidence that our interactions with the physical world are not subject to physical law. Further, there is no 'human factor' to be found in the mathematical structure of quantum mechanics, just as there was no 'ether factor' in electromagnetic theory." P. R. Wallace, p.29 [3].

"The 'hard problem' is easy! It's the 'easy' problems that are hard!" Mike Vandeman [4,5].

I think that there must be very few books that live up to the promise implicit in their title. It is very tempting to exaggerate, in order to get people to buy the book. (By contrast, Walt Whitman's Leaves of Grass, one of my favorite books, does discuss leaves of grass, but also a lot more!) As far as I can tell, Evan Harris Walker's The Physics of Consciousness: Quantum Minds and the Meaning of Life discusses neither the physics of consciousness, quantum minds, nor the meaning of life.

Woven throughout the book is a very charming and entertaining thread devoted to describing Walker's relationship with his high school sweetheart, Merilyn Ann Zehnder, and her tragic death from leukemia. I enjoyed this glimpse into the author's life, but I don't see how it contributed to fulfilling the book's promise. I suppose it gave some "human interest" to a book that otherwise could be too taxing on the brain, or served as a dramatic device -- interrupting the physics thread and creating suspense.

For me, by far the greatest value of the book was the fascinating and very detailed recounting of the history of physics -- especially the description of particle physics and quantum mechanics. It's comforting to know that quantum mechanics and relativity are an accurate reflection of the world -- all of it! It's also fascinating to watch humanity (who, according to Reg Morrison [6] (The Spirit in the Gene), are genetically predisposed to spirituality or religion) be forced to relinquish one myth after another to the persuasive power of science. Walker's writing is lucid and generally easy to understand -- quite a feat, considering the difficulty of the subject matter and the fact that its essence can be expressed only in mathematical form! For me the book brought together numerous disparate bits of physics that I hadn't fully grasped or integrated. For that, I am very grateful.

Walker then takes a giant leap and asserts, without citing any evidence, that consciousness is different from anything ever studied or described by physics -- it's "special". He seems to assume that this is so obvious that it doesn't need proof, but, on the contrary, not only does it require evidence, but it is actually false, which derails the rest of his arguments. Remember, he has just finished describing the fact that current physical theories describe the entire universe (at least since it was $10^{-43}$ seconds old), from subatomic particles to galaxies, with enormous precision! So it is illogical to suddenly claim that there is something -consciousness -- which is not described by those equations! (And yet, he later contradicts himself by equating consciousness with a quantum mechanical "tunneling" of electrons.) That consciousness is "special" is an assumption. If it falls, then the rest of the book -- and probably all other writing and thinking about consciousness -- also falls.

Here are some of Walker's statements in support of this assumption: "Science is incomplete and must be greatly expanded if it is to meet the challenge of this data." (p.159) "If we approach what is in those equations [of physics] exclusively in terms of those ideas physicists have put there, we will see that there are some things that are missing and that cannot be derived from the things that have gone into those equations. The equations have positions and intervals, quantities and forms, and they describe responses. But feelings are not there, nor is pain, $\mathrm{C}^{\#}$, or the colors we see in the budding red rose. 'Motives' are there, but emotions are not. Conscious being is not in these equations. [That is an assumption! In other words, he is begging the question, not answering it.] If consciousness is to play its role in physics, it must be included in its own right, on its own terms. [That's funny -- ethics, philosophy, art, music appreciation, and government are also not in those equations, but no one has ever suggested that we need to expand physics in order to explain them!]. ... It will be necessary to introduce something new into physics on its own terms. This is how it has always been in physics when we have wished to understand something totally new. This is how we must do things now." (p.176) "Consciousness is something that exists in its own right and has its own identity. It is distinct from all other objects, processes, energies, and realities that physics or science as a whole reveals." (p.178) "Consciousness is nonphysical. ... It is real and nonphysical." (p.182) "The classical machine cannot have consciousness, and it cannot have any identity of its own." (p.253).

Walker then describes his theory of the functioning of the synapse, and argues that consciousness is the quantum mechanical "tunneling" of electrons across the synapse: "There, in those minute switches, at the miniscule intersynaptic cleft -- that is where the quantitative link between mind and brain is to be found." (p.194).

${ }^{*}$ Correspondence to: Michael J. Vandeman, The American Biology Teacher, 2600, Camino Ramon \#3s300d, San Ramon, CA, USA, E-mail: mjvande@ pacbell.net

Received: October 02, 2019; Accepted: October 11, 2019; Published: October 14, 2019 
He then goes on to make the absurd assertion that nothing exists until it is observed by a conscious observer! "Only our observation of the object [a die thrown onto a craps table] leads it to take on one out of all its possible orientations and come to rest with one of its six faces up." (p.270) "We have seen matter and space as the natural consequence of nothing more than the fact that conscious observers exist." (p.331) In order to understand this assertion, we need to think about quantum mechanics and the Heisenberg uncertainty principle. Heisenberg showed that when one tries to measure either the location or momentum of an object, the act of measuring itself disturbs the object, so that one can determine either characteristic to arbitrary precision, but not both. This is not simply a defect in our equipment! This is the fundamental nature of matter! For example, if we shoot an electron at a phosphorescent target, until it hits the target and creates a flash of light, it has no position, but exists only as an infinite set of possible locations and momenta, with varying degrees of probability.

But it is not the observer that determines where and how the die will land! It is the table and the forces of gravity and electromagnetism! The observer enters the picture only after the die has settled into its final resting position. This is Walker's means of injecting (human, or at least animal) consciousness (and, ultimately, meaning and God) into physics. It fails. (However, I wish that Walker had spent more time on this matter, since it is the crux of his argument. I had trouble following the part that centered on Bell's Theorem, where supposedly quantum mechanics triumphs, and belief in concrete reality has a stake driven through its heart. This section (Chapter 8 ) was intriguing, but very difficult to understand.)

In mathematics there is a tool called "reductio ad absurdum". One makes an assumption, and then argues logically from that assumption to arrive at a conclusion that is "absurd" (obviously false). That proves that the assumption upon which the argument was based must be false (for example, one can assume that a number exists which is zero divided by zero; from this one can "prove" that $1=2$ ). Thus, in the present case, the assumption that consciousness exists as something "special", not describable by physics, is false: it leads to absurd conclusions.

The other serious error that Walker makes is that he identifies consciousness with wakefulness. The state of being awake, which, according to my physiology text, is controlled by the brain's reticular activating system, is only one meaning of "conscious" ("having mental faculties undulled by sleep, faintness, or stupor: awake" (Webster, p.238)) [7]. The more important use of the word is being conscious of something: "aware of and responding to one's surroundings" (Compact Oxford English Dictionary) [8]. Wakefulness is a necessary (except possibly for dreams), but not a sufficient, condition for being aware of something. Although I am awake, I am rarely aware (conscious) of the traffic outside my house, nor even the temperature of my own skin. I am very good at focusing on one thing, and ignoring everything else. (No wonder we men are so often accused of being "insensitive"!)

A third serious error is that Walker identifies consciousness with something that takes place in a very specific location: the nerve synapse. This would imply that organisms without nerves cannot be conscious. However, Donald Griffin (Animal Thinking) [9] has argued convincingly that thinking (complex decision-making) goes back as far as single-celled organisms, which are aware of chemicals in their environment and respond appropriately -- approaching or avoiding them based on whether they represent food, mate, or threat. Green plants detect (are aware of) sunlight and turn their leaves so as to maximize the energy they receive. Humans are genetically $98.6 \%$ identical with chimpanzees, so it is unlikely that so important a characteristic as consciousness could be present in humans but not in chimps. But we also share a large percentage of our genome with all animals, and in fact with all living things! Since consciousness (awareness of things and events outside the organism) is so integral to all life, it most likely is not simply a matter of nerve synapses, and probably is an essential feature of all living things: "All living beings, not just animals but plants and microorganisms, perceive. ... Mind and body, perceiving and living, are equally self-referring, self-reflexive processes already present in the earliest bacteria". (Margulis \& Sagan, p.32) [10] "Life ... is awareness and responsiveness; it is consciousness and even self-consciousness." (ibid., p.177) "Mobile microbes make selections -- they choose." (ibid., p.179) "The gulf between us and other organic beings is a matter of degree, not of kind." (ibid., p.182) "Thinking and being are the same thing." (ibid., p.188)

So how can we determine what consciousness is? Obviously, the laws of physics that apply within living organisms are identical to the laws that hold outside them. Walker admits that the laws of physics apply to the entire known universe. ("Life is less mechanistic than we have been taught to believe [we obey probabilistic quantum mechanics, rather than the deterministic Newtonian physics]; yet, since it disobeys no chemical or physical law, it is not vitalistic [i.e., there is nothing "magic" or "special" about life]." (Margulis \& Sagan, p.178)) [10] But this implies that there is nothing "special" about life -- nor about consciousness! And it implies that anything that can happen inside a living organism can also happen outside living things (if a distinction between living things and nonliving things even makes sense) -including consciousness! The splitting of $\mathrm{H}_{2} \mathrm{O}$ into hydrogen and oxygen takes place in green plants, but it can also happen outside them. Every event that can happen within a living organism can potentially (given the right conditions) also happen outside them. In fact, if we assume that life and consciousness are "special", then (by reductio ad absurdum) it follows that they don't exist! No wonder they are so hard to define and describe! It is hard to define something that doesn't exist (such as, for example, God)....

So what is consciousness? Simply the registering of an effect. A scale is conscious of weight. It is not conscious of (able to measure) anything else. If it could be arranged so as to weigh itself (I don't know if that is physically possible), then it would be self-conscious (in that one dimension). We are also capable of being conscious of weight. I can feel pressure on my skin from a weight resting on top of it, and I can also hold the weight in my hand and feel the strain on my arm muscles. These are just two possible ways of being conscious of weight, neither of which is the same method used by the scale. I am also conscious of light, which the scale is not. But I am not conscious of ultraviolet radiation, although a bee and a UV meter are. A robot is conscious, but not of enough things to survive on its own -- not enough to survive in this rough-and-tumble world. Humans are visually conscious of the movement of distant objects, but we are nowhere as perceptive as birds. Of course, being conscious of more dimensions doesn't make one superior, except in the narrow sense of those dimensions. Bacteria are undoubtedly superior in their consciousness of chemical nuances. In any case, there are obviously many ways to be conscious, not just one, just as there are many different ways to store information. Consciousness is not a fundamental constituent of reality -- nor anything new or unitary.

To show how life and non-life (whatever they are, if they even exist!) shade into each other, look at a couple of examples. Frogs in Canada freeze solid every winter and thaw out again in the spring. While frozen, they are neither alive (they don't meet any of Margulis and Sagan's criteria, since they are doing absolutely nothing) nor dead (death is, 
by definition, final). Okay, maybe you believe that the frozen frogs are alive, and doing something, although you don't know what. The frogs don't contain much extra energy, so if they were doing anything, all their stored energy would get used up, and they would have none left to allow them to awaken in the spring. If that example doesn't convince you, then look at the seeds stored in the pyramids for 3,000 years. Dead, or alive? Since they were able to germinate upon being given water, they couldn't have been dead, according to Margulis and Sagan and every other biologist. But they can't have been alive either, because if they were doing anything during those 3,000 years, all of their tiny store of energy would have long since been exhausted. Viruses and prions are two more examples of life shading into non-life; viruses are not considered alive, but they perform some of the same functions as living things, such as reproduction. In other words, it is not possible to detect the difference between life and non-life: i.e., there is no real difference! Life is an indefinable state of matter, kind of like (but even less definable than) the liquid- vs. solid state of water.

Thus, the real mystery is not consciousness; the real mystery is how humans can miss what is "hidden" in plain sight -- right in front of our noses! Obviously, we can't know directly whether any other organism is conscious. We can only infer that from its behavior. That goes for our own friends and family, pre-verbal or dumb (unable to talk) humans, animals, plants, bacteria, etc. Bacteria and protists (e.g. protozoa) act as if they are conscious. Or perhaps I should say that we sometimes act like them -- turning our faces toward the sun, sniffing out attractive smells from the kitchen, reacting instinctively to environmental hazards. Try this experiment: turn on the television, but turn off the sound. You will be amazed at the things you become conscious of (the mole on an actor's nose, the blond hair and brown eyebrows, the funny way people move, etc.), that you had been forced to ignore due to trying to follow (be conscious of) the (verbal) story. Meditation is another experiment in consciousness. Try meditating on the self-conscious scale.... It's no wonder that no one has discovered what consciousness is. If consciousness is a white horse (or nothing special at all), but you insist that it is a green dragon, you can look all you want, but you will never find it.

Two more things remain to be discussed: will, and the meaning of life. On page 333 Walker admits: "But for all this terror, there is one thing that is worse: the thought that all the suffering and all the pleasure of life have no meaning." I don't see how the meaning of my life, or any life, depends on the existence or importance of consciousness. While life has no single, canonical meaning (else we would long ago have discovered what it is!), each person's life has -- to them -- the meaning that he or she chooses to give it. (Of course, we get some ideas from others, past or present.) The same goes for morality and ethics: what is moral is what we think (based partially on input from others) is moral. Science and physics have little to do with any of this, except to keep us honest. Science can only tell us what is, never if it should be. Therefore it cannot be blamed for any alleged decline in morality. I suspect that "immorality" is like a recessive gene -- impossible to eliminate. We also can't depend on evolution to "improve" humankind. Evolution is like justice: blind. It only ensures the survival of those who survive -- not necessarily those with any given characteristic (including alleged "fitness", whatever that is).

Then what about free will? (Walker simply refers to "will", and sidesteps this question.) The fall of Newton's deterministic physics, and the triumph of "probabilistic" quantum mechanics, implies that our behavior is neither predetermined nor predictable. (That's nice! It would be pretty boring, otherwise!) The "butterfly effect" rules. But this also doesn't imply that our behavior is under our own control. And since it is apparently decided at a molecular (hence quantum) level, the Heisenberg uncertainty principle prevents us from ever knowing causation for certain. In other words, we probably don't have free will, but we have no way of ever knowing for sure, and we feel that we have free will, so ... who cares? (Well, the criminal justice system may care, thinking that people should only be held responsible for what they deliberately do. But it's impossible to know for sure, and ... nature (evolution) doesn't care.)

In spite of centuries of thought and research into human-, animal, and plant behavior we still don't know why people commit murder -- or much else. Can you resist eating that cookie? If humans were rational, no one would smoke, right? I know that I am irrational, because no matter how often I see people behave irrationally, I still continue trying to treat them as if they were rational, by reasoning with them!

This paper would be incomplete without discussing the purpose of life -- something Walker skipped, even though he is obviously interested in it. The purpose of life is to have fun! I mean, what else could it be?! (Of course, that excludes hurting wildlife or other people, even if you happen to think that that's fun.) And I certainly had fun reading this book, and thinking about it.

\section{References}

1. Walker EH (2000) The physics of consciousness, the quantum minds and the meaning of life. J Parapsych 64: 339-346.

2. Hobson JA (1994) The chemistry of conscious states: Toward a unified model of the brain and the mind. Little, Brown and Co.

3. Wallace PR (2012) Paradox lost: images of the quantum. Springer Science \& Business Media.

4. Vandeman MJ (2001) “The Myth of the Sustainable Lifestyle". Presented at the Society for Conservation Biology meeting, University of Hawaii, Hilo, Hawaii.

5. Vandeman MJ (2002) "What Is Homo Sapiens' Place in Nature, From an Objective (Biocentric) Point of View?" Presented at the Society for Conservation Biology, University of Kent, Canterbury, England.

6. Morrison R (1999) The spirit in the gene: Humanity's proud illusion and the laws of nature. Cornell University Press.

7. Webster's New Collegiate Dictionary (1981) Springfield, MA: G. \& C. Merriam Company.

8. Soanes C, Hawker S, editors. (2005) Compact Oxford english dictionary. United Kingdom: Oxford University Press.

9. Huntingford FA, Donald R Griffin (1984) Animal Thinking, Harvard University Press, Cambridge, Massachusetts.

10. Margulis L, Sagan D (2000) What is life?. Univ of California Press.

Copyright: (C2019 Vandeman MJ. This is an open-access article distributed under the terms of the Creative Commons Attribution License, which permits unrestricted use, distribution, and reproduction in any medium, provided the original author and source are credited. 